\title{
Bright Cool White Emission from Ultrasmall CdSe Quantum Dots
}

Talitha VanWie ${ }^{\text {a,f }}$, Erin Wysocki ${ }^{a}$, James R. McBride ${ }^{\mathrm{a}, \mathrm{e}, \mathrm{f}}$, Sandra J. Rosenthal*a-f

\section{SUPPLEMENTAL INFORMATION}

\section{TEM/STEM Characterization of Ultrasmall CdSe and CdSe-CA Quantum Dots}

TEM of the untreated ultrasmall CdSe QDs shows good monodispersity. After the treatment with citric acid, the TEM shows aggregates of approximately $20 \mathrm{~nm}$ in diameter. When analyzed with STEM, it was found that these aggregates are not larger QDs, but a cluster of the ultrasmall QDs.

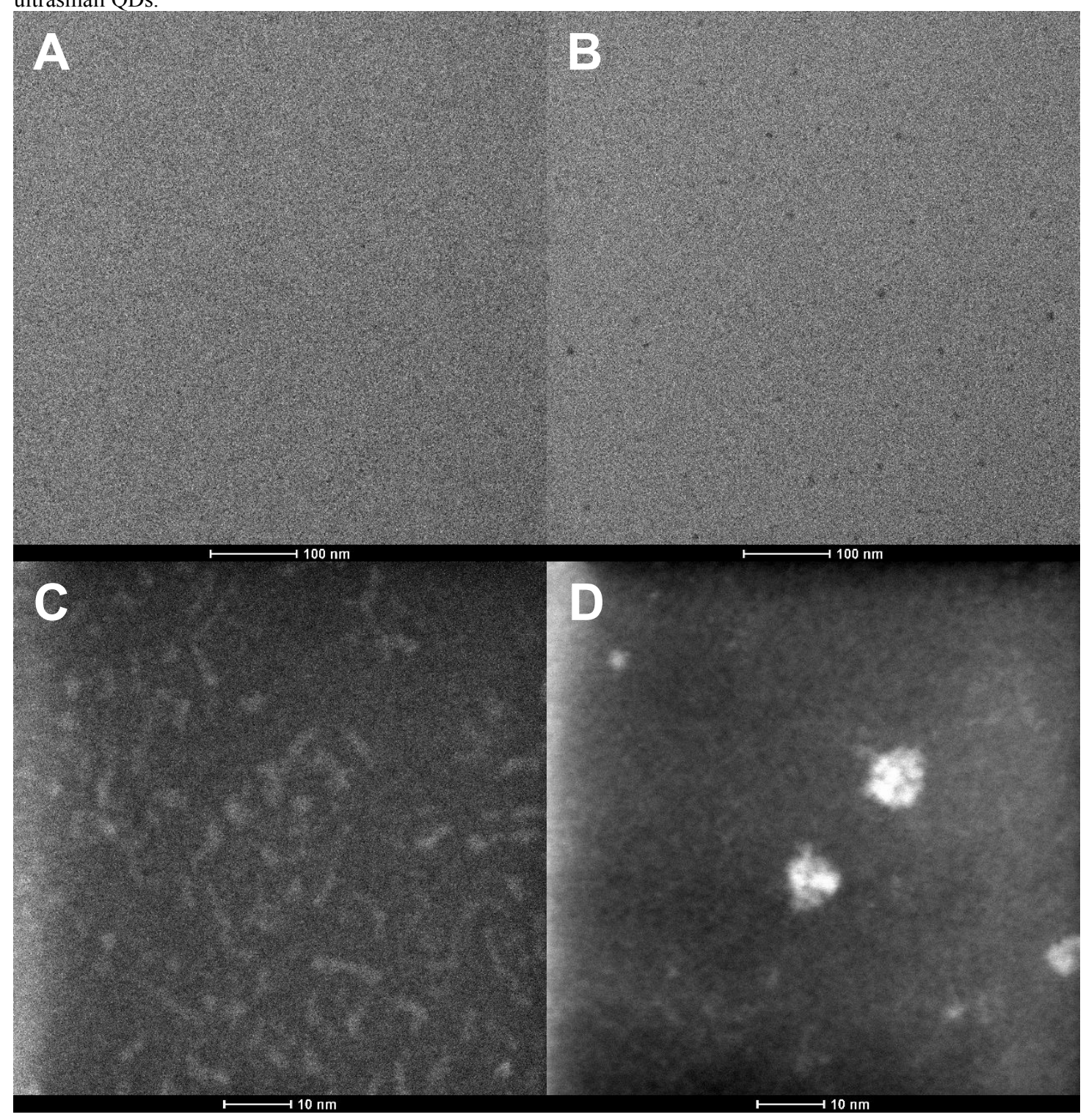

Figure S1. TEM images (A and B) and STEM images of ultrasmall CdSe and CdSe-CA QDs. 
The IR spectra for CdSe QDs (Figure S1) has vibrations characteristic of the stretching and bending modes of the ligands used in the synthesis (Table S1). These peaks are slightly shifted compared to the free molecules due to being either bound to or in close proximity to the QD surface. ${ }^{l}$ After treatment with citric acid, the IR spectrum now shows peaks characteristic of both the citric acid and the ligands used for the CdSe synthesis. ${ }^{2}$ Further, it is seen that the broad -OH peak is no longer visible in the CdSe-CA IR spectrum. This could be due to the way that the citric acid ligand binds to the surface of the QD, but that is beyond the scope of this work.

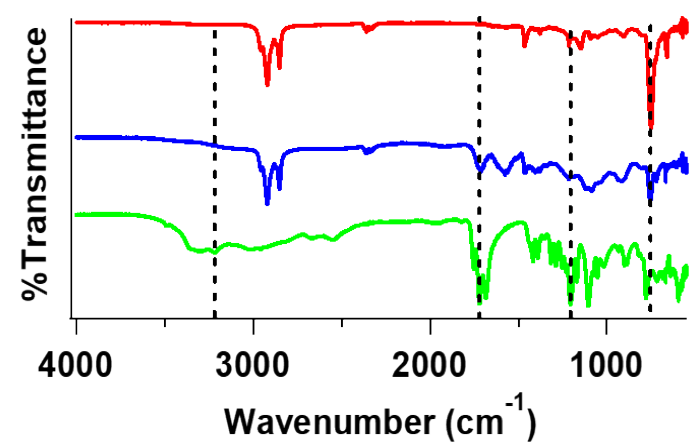

Figure S2. IR spectra for CdSe QDs (red), CdSe-CA QDs (blue), and citric acid. The dashed lines indicate the $\vee \mathrm{O}-\mathrm{H}$ $\left(3217 \mathrm{~cm}^{-1}\right), \vee \mathrm{C}=\mathrm{O}\left(1720 \mathrm{~cm}^{-1}\right), v \mathrm{C}-\mathrm{O}\left(1220 \mathrm{~cm}^{-1}\right)$, and the $v$ P-C $\left(750 \mathrm{~cm}^{-1}\right)$.

Table S1. Peak assignments for CdSe QDs, CdSe-CA QDs, and citric acid.

\begin{tabular}{|c|c|}
\hline \multicolumn{2}{|l|}{ CdSe QDs } \\
\hline Wavenumber $\left(\mathrm{cm}^{-1}\right)$ & Assignment \\
\hline 3320 & $v_{\mathrm{s}} \mathrm{NH}$ \\
\hline 2960,2910 & $v_{\mathrm{s}} \mathrm{CH}_{3}, v_{\mathrm{as}} \mathrm{CH}_{3}$ \\
\hline 2920,2850 & $v_{\mathrm{as}} \mathrm{CH}_{2}, v_{\mathrm{s}} \mathrm{CH}_{2}$ \\
\hline 2360 & $v \mathrm{PO}-\mathrm{H}$ \\
\hline 1580 & $\delta \mathrm{NH}_{2}$ \\
\hline 1150 & $v \mathrm{P}=\mathrm{O}$ \\
\hline 1090,1050 & $v_{\mathrm{s}} \mathrm{P}-\mathrm{OH}, v_{\mathrm{as}} \mathrm{P}-\mathrm{OH}$ \\
\hline 750 & $v \mathrm{P}-\mathrm{C}$ \\
\hline \multicolumn{2}{|l|}{ CdSe-CA QDs } \\
\hline 1720 & $v \mathrm{C}=\mathrm{O}$ \\
\hline 1580 & $\delta \mathrm{NH}_{2}$ \\
\hline 1220 & $v \mathrm{C}-\mathrm{O}$ \\
\hline 1090 & $v \mathrm{P}-\mathrm{OH}$ \\
\hline 754 & $v \mathrm{P}-\mathrm{C}$ \\
\hline \multicolumn{2}{|l|}{ Citric Acid } \\
\hline 3217 & $v \mathrm{O}-\mathrm{H}$ \\
\hline 1720,1715 & $v_{\mathrm{as}} \mathrm{C}=\mathrm{O}, v_{\mathrm{s}} \mathrm{C}=\mathrm{O}$ \\
\hline 1205 & $v \mathrm{C}-\mathrm{O}$ \\
\hline 1104 & $v \mathrm{C}-\mathrm{OH}$ \\
\hline
\end{tabular}




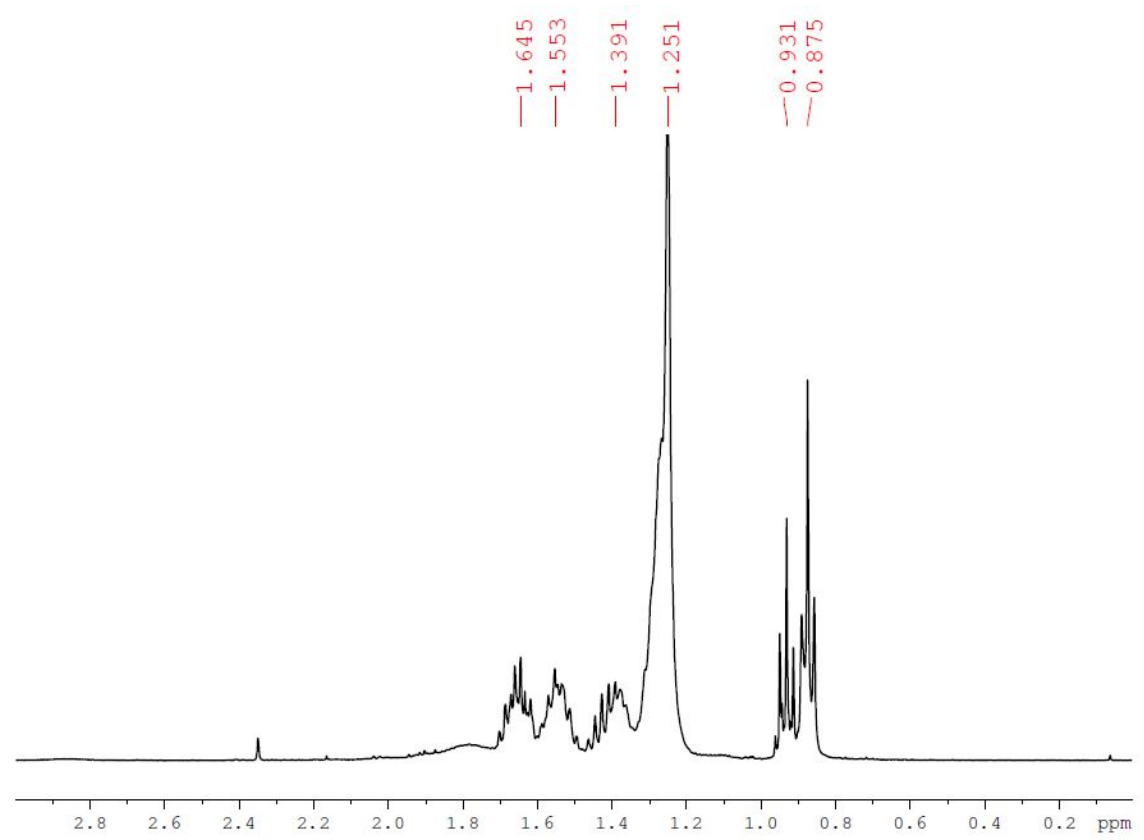

Figure S3. Ultrasmall CdSe QDs in CDCl3 1H NMR. Labeled peaks are from the aliphatic protons on the carbon chains of the TOPO, HDA, and DDPA ligands.
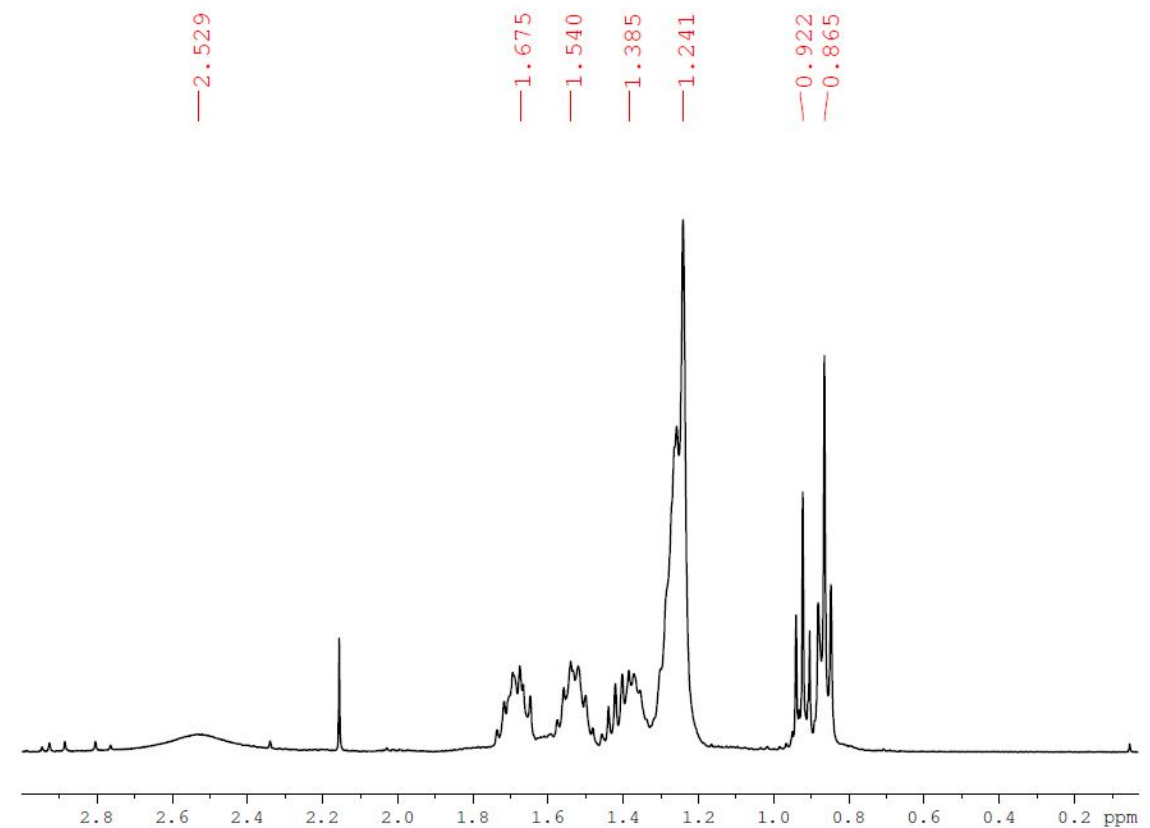

Figure S4. Ultrasmall CdSe-CA QDs in CDCl3 1H NMR. Labeled peaks are from the aliphatic protons on the carbon chains of the TOPO, HDA, and DDPA and CA ligands. 


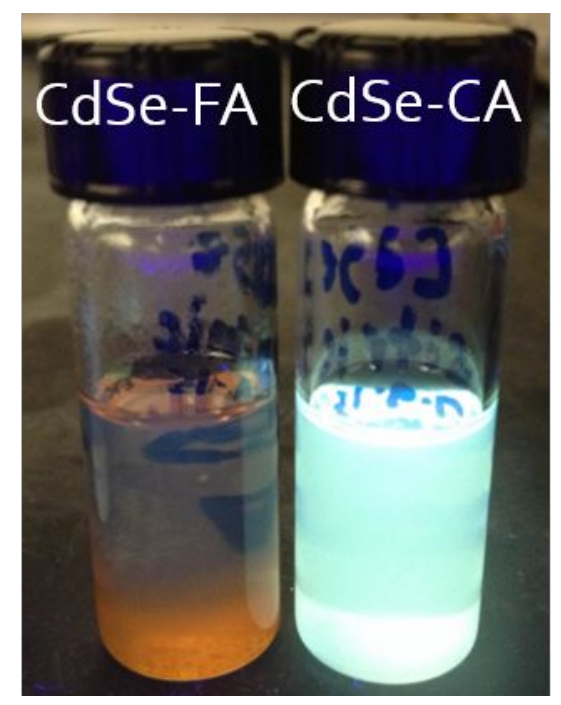

Figure S5. Comparison of CdSe-FA and CdSe-CA QDs after 25 days. The fluorescence of the CdSe-FA QDs has completely quenched, whereas the CdSe-CA QDs have a QY of $29.9 \%$.

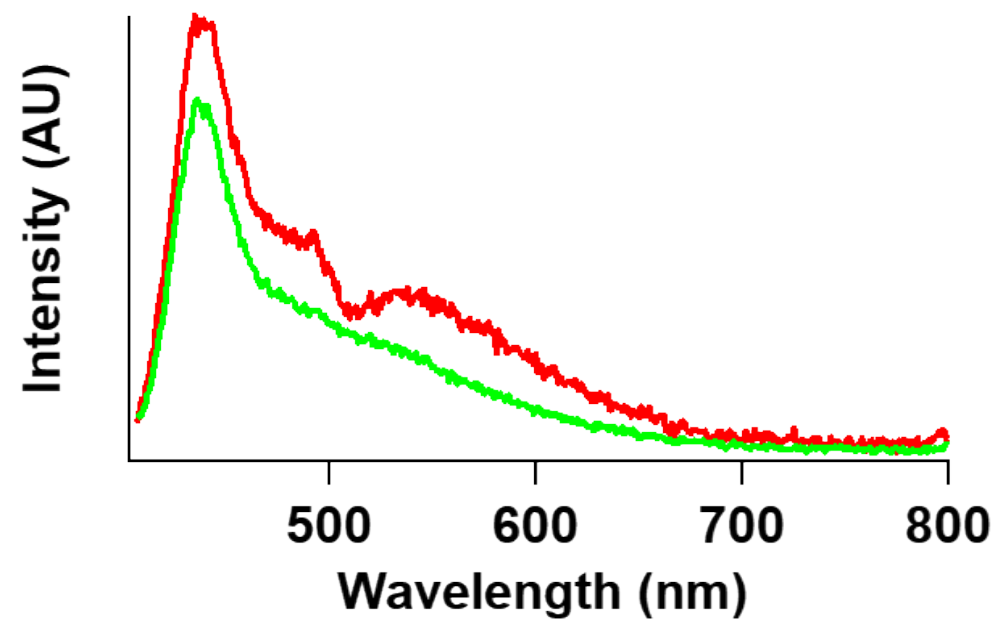

Figure S6. CdSe-CA QDs PL spectra immediately after synthesis (red) and after 21 days (green).

(1) Zeng, B.; Palui, G.; Zhang, C.; Zhan, N.; Wang, W.; Ji, X.; Chen, B.; Mattoussi, H. Characterization of the Ligand Capping of Hydrophobic CdSe-ZnS Quantum Dots Using NMR Spectroscopy. Chem. Mater. 2018, 30, $225-238$.

(2) Pimpang, P.; Sumang, R.; Choopun, S. Effect of Concentration of Citric Acid on Size and Optical Properties of Fluorescence Graphene Quantum Dots Prepared by Tuning Carbonization Degree. Chiang Mai J. Sci. 2018, 45, 2005-2014. 